\title{
SMART HEALTHCARE FOR PATHOLOGY DETECTION AND MONITORING
}

\author{
D. Mohana Priya, P. Mathivanan \\ Assistant Professor, Department of Information Technology, \\ Manakula Vinayagar Institute of Technology, Puducherry \\ B. Durga, K. Calpana, R. Lara Iyswarya Rane \\ Student, Department of Computer Science and Engineering, \\ Manakula Vinayagar Institute of Technology, Puducherry
}

\begin{abstract}
The undertaking presents the cognitive smart health care services structure that embraces the Internet of Thing (IOT) cloud innovations. This system utilizes keen sensors for interchanges and profound learning for canny dynamic inside the shrewd city point of view. Liquor addiction is a confusion described by over the top utilization and reliance on liquor. There are different approaches to distinguish whether a patient is dependent on liquor, and recognizing the temperature of that individual utilizing internal heat level sensor(EEG). Liquor compulsion can cause a few negative factors and dangers that incorporate mental issue, for example, stress, misery, tension issue, or schizophrenia. There are different approaches to identify whether a patient has been dependent on liquor, one of them by distinguishing the liquor abuse utilizing liquor sensor. Furthermore, checking the heart beat waves utilizing Electrocardiogram sensor(ECG) Therefore, this exploration actualizes Wavelet Packet Decomposition (WPD) strategy for include extraction, Principal Component Analysis (PCA) for measurement decrease, and Back Propagation Neural Network advanced with Genetic Algorithm for liquor compulsion order.
\end{abstract}

Key Words: Electrocardiogram sensor, Alcohol Sensor, psychological disorders, Node MCU, Heart beat Sensor, Temperature Sensor.

\section{INTRODUCTION}

The Internet of Things (IoT) has changed from being an interconnection of implanted registering gadgets to an interconnection of keen sensor gadgets Real-time correspondence and patient screen ing have consistently been the focal thought of brilliant medicinal services administrations. Nonetheless, with IoT cloud advancements, the requirement for a subjective structure that gives understanding driven and top notch shrewd human services effortlessly increments. With man-made brainpower (AI) and profound learning strategies, acquainting human-like insight with brilliant medicinal services structures is convenient. IoT and cloud innovations have as of late observed generous headways and have given continuous shrewd medicinal services administrations.

With IoT cloud coordination, the interest for an omnipresent savvy medicinal services structure that gives consistent and quick reaction is extensive.

IoT gadgets can likewise be utilized to control basic foundation like extensions to give access to ships. Use of IoT gadgets for observing and working foundation is probably going to improve episode the executives and crisis reaction coordination, and nature of administration, up-times and diminish expenses of activity in all framework related territories. Indeed, even regions, for example, squander the board can profit by mechanization and improvement that could be gotten by the IoT.

Computerized control frameworks to mechanize process controls, administrator devices and administration data frameworks to streamline plant wellbeing and security are inside the domain of the IoT. Be that as it may, it additionally stretches out itself to resource the executives through prescient support, factual assessment, and estimations to augment unwavering quality. Keen modern administration frameworks can likewise be incorporated with the Smart Grid, accordingly empowering ongoing vitality improvement. Estimations, robotized controls, plant improvement, wellbeing and security the board, and different capacities are given by countless organized sensors.

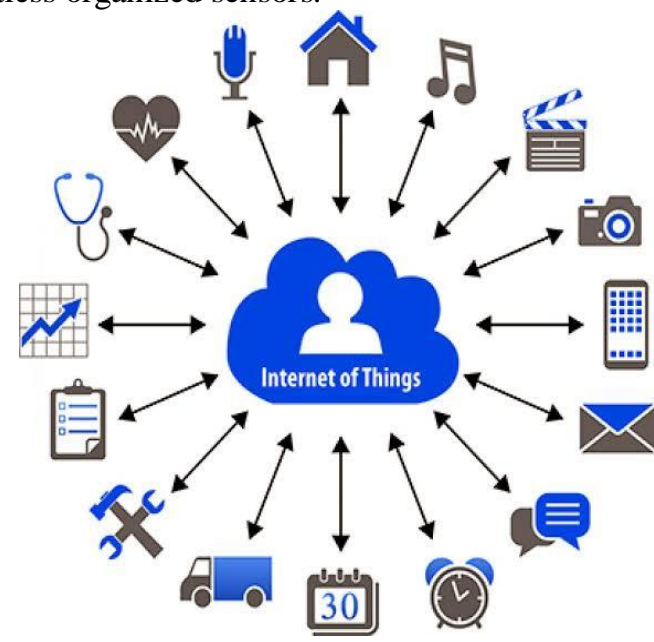

Fig-1: Internet of Things 


\section{International Journal of Engineering Applied Sciences and Technology, 2020 \\ Vol. 4, Issue 12, ISSN No. 2455-2143, Pages 223-230 \\ Published Online April 2020 in IJEAST (http://www.ijeast.com)}

The IoT will associate a few sensors to give social insurance administrations. Every sensor needs to have an exceptional personality over the web. In this manner, a proficient naming and character the board framework is required that can powerfully dole out and oversee one of a kind personality for such an enormous number of sensors.[7].

The human services industry is presently one of the quickest developing finishes with significant requests. In addition to the fact that it provides significant and basic administrations to patients; it likewise carries enormous incomes to the well being area.

Social insurance suppliers contend in giving reliable and minimal effort human services administrations to keen city occupants [2]. Subsequently, the mix of IoT cloud innovations has additionally been under research concentrate as of late. Advanced and minimal effort keen IoT medicinal services gadgets and savvy human services sensors are being utilized for this reason, including brilliant wearable gadgets for observing heartbeat, liquor abuse, internal heat level, stress, and ECG.

Sensors used to the examination: Using a sensor: Heart Beat can be estimated dependent on optical force variety as light is dispersed or assimilated during its way through the blood as the heart beat changes Pulse Sensor is an all around structured attachment and-play pulse Sensor

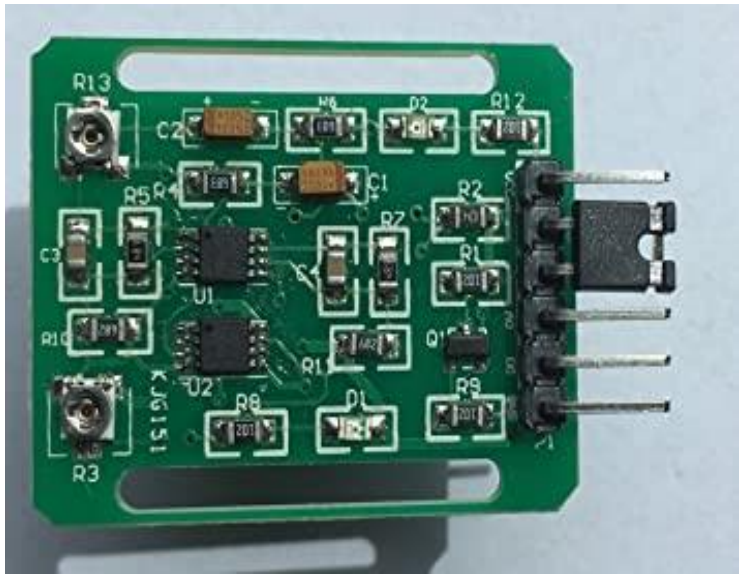

Fig-2: Heartbeat Sensors

LM35 is a temperature measuring device having an analog output voltage proportional to the temperature. It provides output voltage in Centigrade (Celsius). The sensitivity of LM35 is $10 \mathrm{mV} /$ degree Celsius. As temperature increases, output voltage also increases.

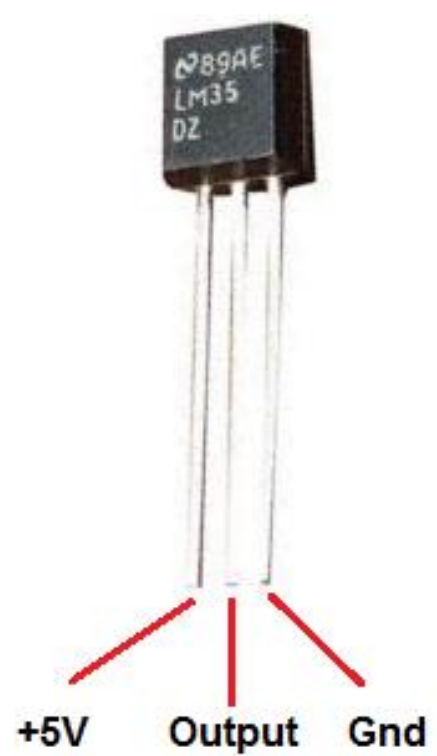

Fig-3: Temperature Sensors

A liquor sensor distinguishes the mindfulness of liquor gas noticeable all around and a simple voltage is a yield perusing. The sensor can initiate at temperatures going from - 10 to $50^{\circ} \mathrm{C}$ with a force supply is under $150 \mathrm{Ma}$ to $5 \mathrm{~V}$. The detecting range is from $0.04 \mathrm{mg} / \mathrm{L}$ to $4 \mathrm{mg} / \mathrm{L}$, which is reasonable for breathalyzers.

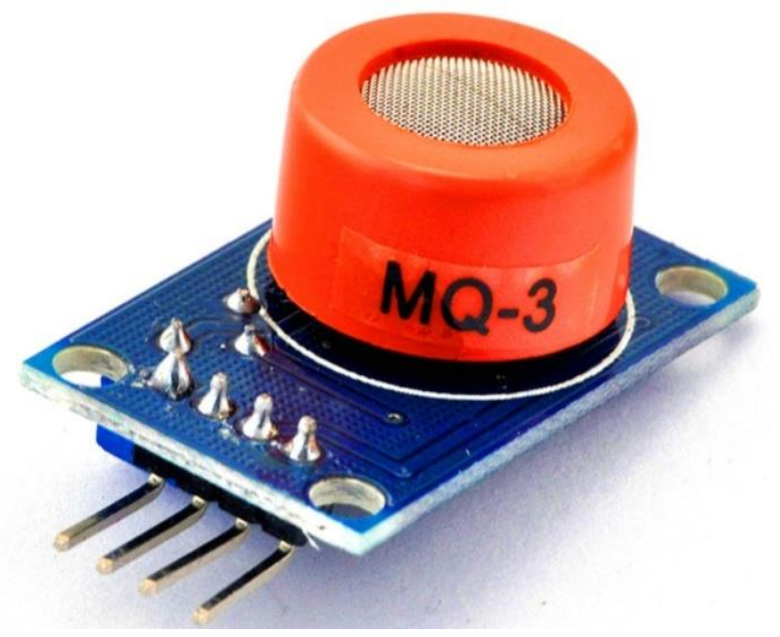

Fig-4: Alcohol Sensors

ECG records the electrical action created by heart muscle depolarizations, which engender in throbbing electrical waves towards the skin. ... ECG cathodes are commonly wet sensors, requiring the utilization of a conductive gel to build conductivity among skin and anodes.

NodeMCU is an open-source firmware and advancement unit that encourages you to model or construct IoT items. It incorporates firmware that sudden spikes in demand for the ESP8266 Wi-Fi SoC from Espressif Systems, and equipment which depends on the ESP-12 module.It depends on the eLua venture and based on the Espressif Non-OS SDK for ESP8266. 


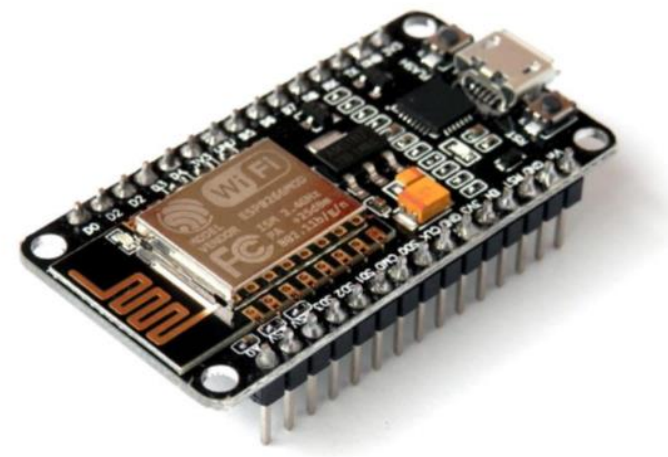

Fig-5: NodeMCU (ESP8266)

The GPS recipient gets a sign from every gp satellite. The satellites transmit the specific time the signs are sent. So given the movement time of the GPS signals from three satellites and their accurate situation in the sky, the GPS recipient can decide your situation in three measurements east, north and height

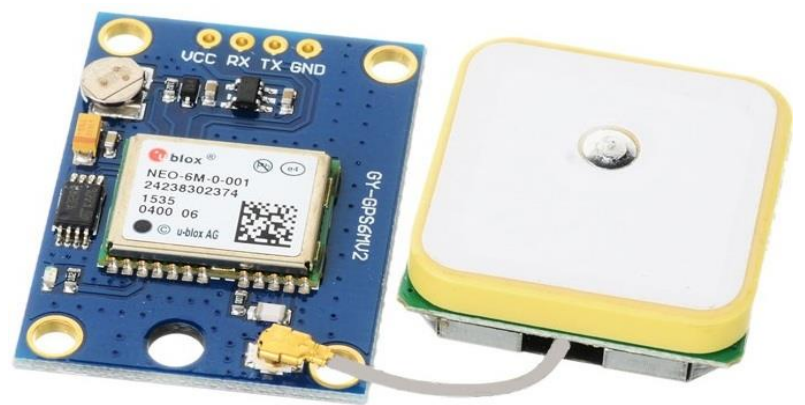

Fig-6: GPS

The blend of these sensors getting information from the individual. So as to do this, Node gathers the wellbeing information of the people from the sensors and it is shown on the server. For the security and wellbeing issues, a job based client validation framework is likewise accessible in the framework to get to the area. Likewise, the NodeMCU consequently identify the anxiety as per the wellbeing state of the people.

\section{LITERATURE SURVEY}

P Kumar et al. [3] has proposed a raspberry pi controlled patient checking framework where heartbeat, breath, temperature and body development of the patient is being estimated utilizing sensors and showed on the screen utilizing the clay programming. Notwithstanding, it doesn't contain the alert notice for giving recommended medications to the patient which has been included our proposed arrangement.

The recently proposed zone, right now, the initiation of alert to give the endorsed medication in time, which will be shown in the LCD show. This caution warning will decrease the human mistake and help the clinical right hand or mindful individual to deal with the patient all the more effectively. The extra and another useful piece of the framework is the way toward sending an email alarm and SMS ready utilizing a python content to specialist, clinical colleague and family members of the patient if any of the deliberate physiological parameters cross the edge esteem. Another one of a kind piece of the proposed arrangement is to make the ideal environmental factors according to the necessity of patient's wellbeing condition whichcan be achieved by sending the deliberate information to the control unit of the framework which thusly, similar to a coding content will convey to the patients. Because of the quick advances in innovation and modern foundation, IoT is relied upon to be generally applied to the ventures. IoT coordinates different gadgets furnished with detecting, recognizable proof, preparing, correspondence, and systems administration capacities. Enterprises have a solid enthusiasm for sending IoT gadgets in the social insurance zone to create human services applications and administrations, for example, mechanized observing [4]. The principle commitment of this audit paper is to examine how IoT could be valuable and add to improve the personal satisfaction.

Freddy Jimenez et al. [5] have concentrated on observing the wellbeing of a patient and sending significant updates and cautions to specialists, relatives and other notable individuals. Nonetheless, it does exclude the apparatus control part, which has been included our task, it just arrangements with the Monitoring part and illuminating the important individuals about it.

\section{A. ROLE OF RASPBERRY PI IN HEALTHCARE:}

The Health Monitoring and information assortment module comprises of all the underneath referenced sensors that would gather the information for example the wellbeing parameters from the patient. Basic wellbeing parameters like pulse, circulatory strain, breath, temperature, glucose level, development of the patient's and saline level could be observed by different sensors accessible inside the proposed framework. Subsequent to accepting the signs from these sensors, it will be sent to the Raspberry Pi. Raspberry Pi runs on a Linux based working framework named as Raspbian and it can work like a little PC[4]. It is essential to keep the records of the clinical information of a patient as it very well may be monstrously helpful in future.

The capacity of information will empower the patient to take a few choices like whether they have to shed pounds or not, which medications are the explicitly unfavorably susceptible for the patient, which sickness are they increasingly inclined to and a lot other fundamental data. This database could likewise assist the specialist with interpretting the physical issue of the patient and its source, which will prompt better analysis and quicker recuperation if there should arise an occurrence of a significant medical problem. This could be accomplished by putting away the information in a content in the cloud through Raspberry Pi module [4]. 


\section{International Journal of Engineering Applied Sciences and Technology, 2020 \\ Vol. 4, Issue 12, ISSN No. 2455-2143, Pages 223-230 \\ Published Online April 2020 in IJEAST (http://www.ijeast.com)}

Boyi $\mathrm{Xu}$ et al. [6] set forward the test of perusing and putting away information in the IoT stage and approaches to unravel it. As we probably am aware the vast majority of the IoT based frameworks remember perusing ongoing information for ordinary interims and social insurance is one of such cases. Under this situation because of the various types of information and customary contribution of information it turns out to be increasingly hard to decipher and consecutively store the information in appropriate arrangement. Subsequently this paper gives us a technique to do that.

\section{B. CLINICAL SENSORS:}

Large information, Cloud Computing, RFID, WSN, Bluetooth, WI-Fi, and the significant clinical sensors. Additionally, the most recent undertakings in the medicinal services region are examined [7]. At long last, it features the significant difficulties in IoT-based frameworks for medicinal services. The presentation of the leaving IoT human services frameworks should be improved by presenting upgrade strategies and systems [8]. These will be considered as a future work.

\section{EXISTING SYSTEM}

The human services office makes the world exceptionally valuable and numerous advantages are accommodated different medical clinics and doctors. Patients from various issues safeguarded from the specialists by the medicinal services offices. To detect the heart beat issues heart beat sensor has been presented. Whatever the issue in heart the sensor makes unmistakable to the doctor. The doctor recognizes the circumstance happened for the patient and proceeds onward further methodology.

The framework for a shrewd city needs its inhabitants to enlist for its administrations. The enrollment procedure sets up a safe channel among occupants and social insurance specialist co-ops and empowers every single approved partner to utilize the psychological module to remotely recover understanding subtleties and wellbeing records. The patient's area is persistently followed to offer assistance if there should arise an occurrence of crisis. Mental and physiological signs are recorded progressively and the patient's state is constantly checked.

\section{A. IDENTIFICATION OF PATIENTS' STATE:}

Patients' developments, facial feelings, voice, and motions are likewise recorded. Patients with cerebrum issue These information which are as wellbeing records, are imparted to medicinal services professionals for point by point investigation. In the event of crises, alarms and alerts are produced by the intellectual framework, and a savvy emergency vehicle or versatile center can find and go to the patient in least time. The shrewd traffic framework additionally aids clinical administrations to arrive at the spot in least time by means of the most limited course.
Social insurance utilizes IoT for ongoing following of patients and clinical gadgets. Instances of IoT Healthcare use cases incorporate the accompanying; Fall recognition, which is viewed as a primary general wellbeing concern. Over ongoing years, the quantity of organizations that offer frameworks and administrations planned at identifying falls has expanded profoundly. Fall recognition frameworks, regularly worn around the abdomen or neck; incorporate astute accelerometers that separate ordinary exercises from real falls. These frameworks are as of now improving the personal satisfaction of many debilitated or older individuals living autonomously. Following of clinical gadgets, it is extremely basic for clinics, particularly in jam-packed crisis rooms with huge clinical staff. IoT arrangements are being utilized to distinguish the specific area of such gadgets, recognize last client.

\section{B. ROLE OF IOT IN HEALTHCARE FIELD:}

IoT-based human services frameworks include various innovations that permit IoT gadgets to acquire information from the physical world, for example, remote clinical sensors, Radio-Frequency Identification (RFID), Cloud Computing, Near-Field Communication, Big information, Wi-Fi, ZigBee, Bluetooth, two-dimensional code gear, etc. This segment will concentrate on a few center advances that have the potential insurgency to IoT based social insurance administrations.

Making IoT arranges progressively reliable is a basic component in medicinal services applications. One route towards accomplishing this objective is to expand the perceivability into the activity of the system to framework administrators, analysts, and engineers. Run-time affirmation venture offers a help in the E-care@home framework. This administration constantly attempts to find and report execution issues and framework mistakes. Also, the center usefulness of the RTA undertaking can be abridged as follows: screen an assortment of interior and outer working conditions intermittently, break down the gathered information to discover current execution debasements, or changes in the condition that may influence future execution, and report significant data to a framework administrator. The difficulties of building a foundation for RTA are: recognizing which conventions and parameters must be checked, with low covering of information that depict a similar condition, the observing must be led with low overhead and with least interference of customary application-layer information bundles, the RTA must involve equal checking endeavors on the serverside.

The framework of the RTA framework comprises of four unique parts that address these difficulties: RTA for sensor stages, database stockpiling of RTA data, RTA at the server-side, and a graphical UI for RTA. These segments offer a support for all pieces of an e-wellbeing framework, including static sensor hubs for ecological checking, portable sensor hubs for wellbeing parameter observing, and the information assortment server for the previously mentioned sensor hubs. 


\section{International Journal of Engineering Applied Sciences and Technology, 2020 \\ Vol. 4, Issue 12, ISSN No. 2455-2143, Pages 223-230 \\ Published Online April 2020 in IJEAST (http://www.ijeast.com)}

\section{LAYERS OF INTERNET OF THINGS:}

IoT interface billions or trillions of heterogeneous gadgets through the Internet, so that there is a basic requirement for a made sure about and adaptable design. In IoT social insurance benefits, the design is one of the most essential components. It assists with getting to the spine, and receipt the clinical information by utilizing a few applications. Right now, and clinical sensors are associated together for patients. It is liable for changing over patient's information into signals that can be transmitted in systems and read by clinical applications. This layer needs Standardized fitting and-play systems to arrange heterogeneous gadgets. Additionally, it needs secure channels to digitize and move information between different layers.

This layer empowers the IoT social insurance applications to work with heterogeneous gadgets without thought to a particular equipment stage. Likewise, this layer forms the information which got from the Application layer, deals with the general IoT social insurance framework, decides, and conveys the necessary administrations over the system wire conventions. There are immense measures of touchy patient's information crossing the IoT human services organize each moment. Observing and controlling these information and the basic layers is accomplished at this layer of IoT arrange. This layer is critical for IoT, it liable for information taking care of, information organization, administration memberships, information move, information get to control, and personality security. It likewise contrasts the yield of each layer and the normal yield to upgrade benefits and keep up clients' security. In addition, this layer ought to accomplish the IoT significant level security prerequisites which are: Data Confidentiality: It guarantees that the traded messages can be seen distinctly by the planned elements. Information Integrity:

It guarantees that the traded messages were not changed/altered by an outsider. Verification: It guarantees that the elements engaged with any activity are who they guarantee to be. A disguise assault or a pantomime assault ordinarily focuses on this prerequisite where a substance professes to be an element. It guarantees that the administration isn't intruded. Forswearing of-administration assaults focus on this prerequisite as they cause administration disturbance.

\section{Approval}

It guarantees that elements have the necessary control consents to play out the activity they solicitation to perform. Freshness: It guarantees that the information is new. Replay assaults focus on this prerequisite where an old message is replayed so as to restore a substance into an old state. Non-Repudiation: It guarantees that a substance can't deny an activity that it has performed. (8) Forward and Backward Secrecy: Forward mystery guarantees that when an element leaves the system, it won't comprehend the interchanges that are traded after its takeoff. In reverse mystery guarantees that any new element that joins the system won't have the option to comprehend the interchanges that were traded before joining the system.

Social insurance suppliers and patients can collaborate with gadgets and inquiry for intriguing information and various administrations by means of this layer by utilizing medicinal services application. It additionally gives an interface to the administration Layer where elevated level examination and reports can be created. This layer performs intricate and huge computational needs so it is facilitated on ground-breaking gadgets. At the end of the day, this layer gives a typical arrangement of administrations that empowers a social insurance application to interface with possibly any gadget without understanding an earlier the particulars and internals of that gadget.

\section{SYSTEM IMPLEMENTATION}

\section{A. PROPOSED SYSTEM}

This system is made utilizing Alcohol Gas Sensor MQ3. It is a minimal effort semiconductor sensor which can identify the nearness of liquor gases at fixations from $0.05 \mathrm{mg} / \mathrm{L}$ to $10 \mathrm{mg} / \mathrm{L}$. The delicate material utilized for this sensor is $\mathrm{SnO}$, whose conductivity is lower in clean air. Its conductivity increments as the convergence of liquor gases increments.. It has high affectability to liquor and has a decent protection from unsettling influences because of smoke, fume and gas.

It gives both advanced and simple yields. MQ3 liquor sensor module can be effectively interfaced with Microcontrollers and Node Mcu. This liquor sensor is appropriate for recognizing liquor fixation on your breath, much the same as your normal breath analyser. It has a high affectability and quick reaction time sensor gives a simple resistive yield dependent on liquor fixation. The drive circuit is straightforward, every one of its needs is one resistor. A straightforward interface could be a $0-33 \mathrm{~V}$ ADC.

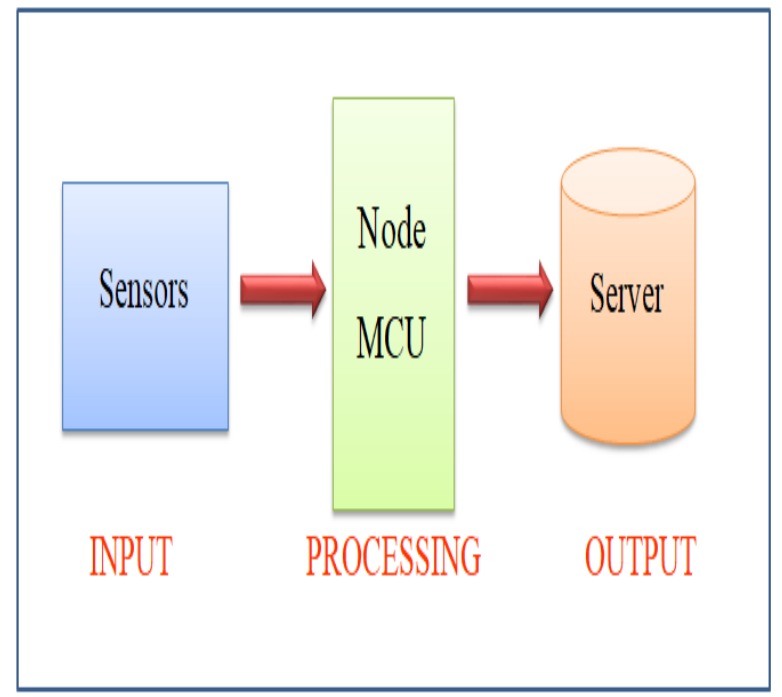

Fig -7: Block Diagram of NodeMCU 


\section{International Journal of Engineering Applied Sciences and Technology, 2020 \\ Vol. 4, Issue 12, ISSN No. 2455-2143, Pages 223-230 \\ Published Online April 2020 in IJEAST (http://www.ijeast.com)}

\section{B. LIQUOR ADDICTION:}

Liquor addiction is said to exist when at least two of the accompanying conditions are available: an individual beverages a lot of liquor over quite a while period, experiences issues chopping down, securing and drinking liquor takes up a lot of time, liquor is firmly wanted, utilization results in not satisfying duties, use brings about social issues, use brings about medical issues, use brings about unsafe circumstances, Environmental elements and hereditary qualities are two segments related with liquor addiction, with about a large portion of the hazard ascribed to each.

Somebody with a parent or kin with liquor addiction is three to multiple times bound to turn into a drunkard themselves. Natural variables incorporate social, social and conduct impacts. Counteraction of liquor addiction might be endeavored by managing and constraining the offer of liquor, to build its expense, and giving reasonable treatment.

Treatment of liquor addiction may take a few structures. Because of clinical issues that can happen during withdrawal, ought to be painstakingly controlled. One basic technique includes the utilization of meds, for example, stomach These can be either given while admitted to a social insurance organization or once in a while an individual stays in the network with close supervision. Psychological instability or other may muddle treatment. After detoxification, or are utilized to help shield an individual from coming back to drinking.

The web of things has been moved from savvy sensor target gadgets to registering gadgets. These frameworks are as of now improving the personal satisfaction of many crippled or older individuals living freely. Following of clinical gadgets, it is exceptionally fundamental for emergency clinics, particularly in packed crisis rooms with huge clinical staff. Web of things arrangements are being utilized to recognize the specific area of such gadgets, distinguish last client.

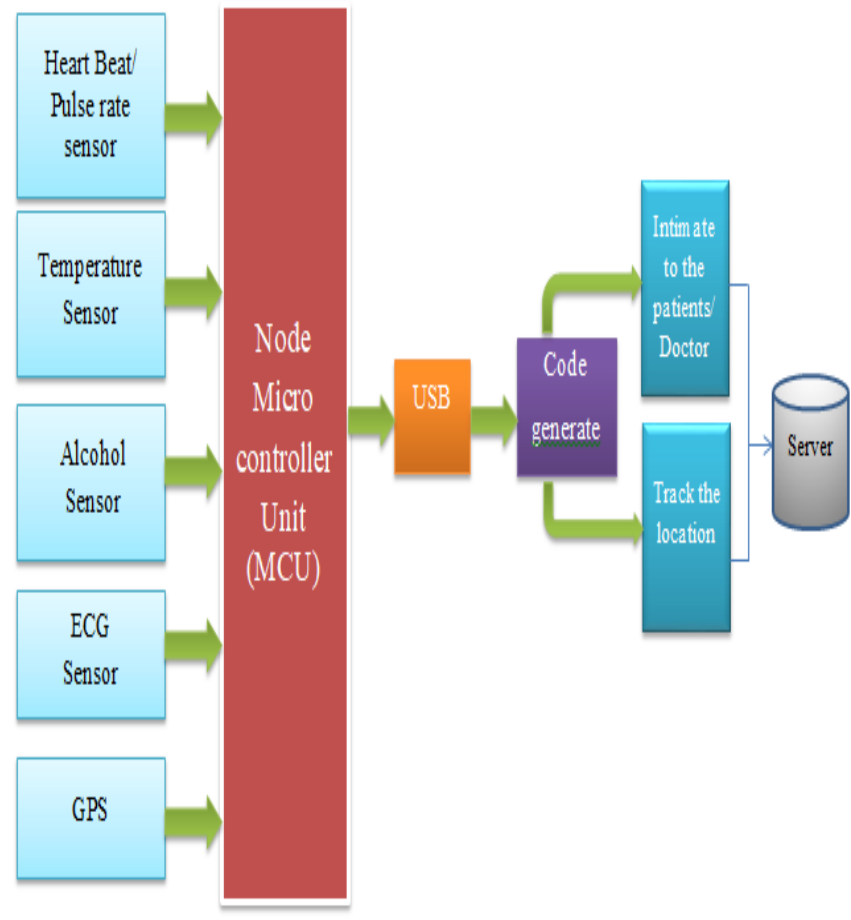

Fig-8: Working of NodeMCU

To build up the improvement of life the innovation is adjusted is known as Internet Of Things. Web of things is a web association of keen gadgets gathering data and the board of items. These days interconnection of gadgets is bigger when contrasted with the number of inhabitants in individuals. As indicated by progression of innovation cost of drugs and human services developing increasingly more most likely

The Mobile based web of things development framework gave an enormous opening for existing strategies that requires for utilization of social insurance utilizing web of things. The great method for web of things is human can get to the web association o things at anyplace and whenever. The web of things isn't just to interface things yet in addition for trade and collaborate information with clients.

\section{EXPERIMENTAL RESULT}

With the power of alcohol sensor it is detected that the person consume alcohol and the immediate precaution can be taken by their respective doctors or members. The sensors helps to recognize the persons state and the alcohol consumed by the person can be recognized through the alcohol sensor. 


\section{International Journal of Engineering Applied Sciences and Technology, 2020 \\ Vol. 4, Issue 12, ISSN No. 2455-2143, Pages 223-230 \\ Published Online April 2020 in IJEAST (http://www.ijeast.com)}

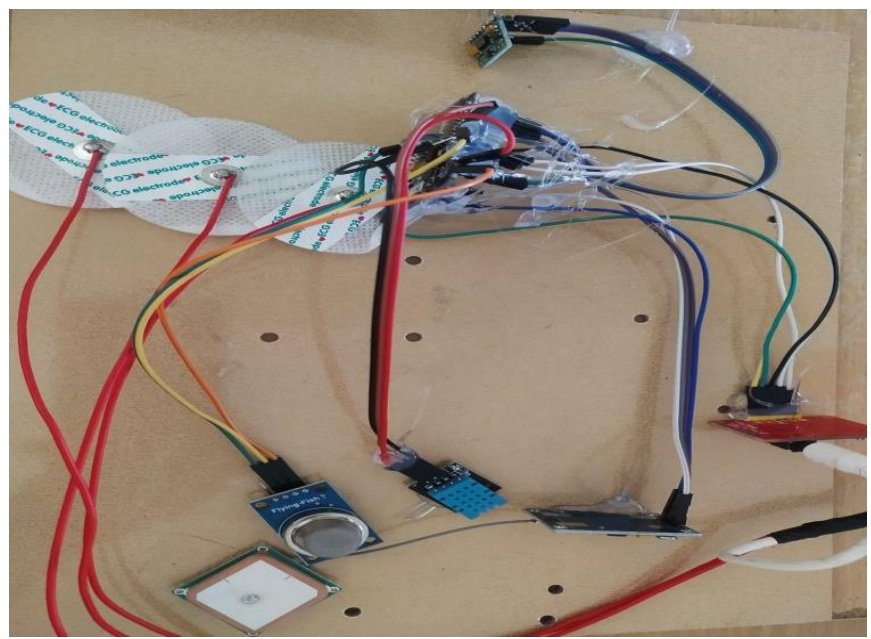

Fig-9: Alcoholic Detection Kit

The alcohol sensor detects the person state who consumes alcohol and immediately the green light will be visible if the person consumes. The temperature and heart beat sensor detects the heart beat range and body temperature so that the doctors can easily identify the person's state. The global positioning system tracks the patients location so that the respective members who had connection with that alcoholic person will know the place or location and immediately rescue them. The global positioning system helps to find the location of the alcohol consuming person.

\section{CONCLUSIONS}

IoT is required to be generally applied to the businesses. IoT coordinates different gadgets outfitted with detecting, recognizable proof, handling, correspondence, and systems administration abilities. Ventures have a solid enthusiasm for conveying IoT gadgets in the social insurance region to create human services applications and administrations, for example, robotized observing. The fundamental commitment of this audit paper is to research how IoT could be helpful and add to improve the personal satisfaction. The keen social insurance framework makes the doctor and individuals increasingly valuable and distinguishing liquor addiction make the viable method for innovation and numerous complaints are diminished. This savvy social insurance framework assists with diminishing issues of patient who devour liquor and followed the patient's state and report quickly about the patients area. This framework makes increasingly advantageous and forestall progressively inadvertent issues.

\section{FUTURE ENHANCEMENT}

The goal of our work is to investigate the recognition of day by day life social utilizing cell phone and their utility in recognizing drinking events. Cell phones have worked in sensors that can possibly be helpful in observing standards of conduct related with the commencement of drinking events. It can likewise decide the anxiety of the individual utilizing EEG savvy sensor for correspondence and profound learning for insightful dynamic. It assists with checking the individual's outward appearance and motions and the EEG flags too. The EEG preparing results are imparted to human services suppliers and quickly give crisis help. This structure diminishes suicide levels and to keep away from the greater part of the burdens and to accomplishes better exactness.

\section{REFERENCES}

[1] John D Clapp, James Lange, Jon Wong Min, Audrey Shillington, Mark Johnson and Robert Voas. 2003. Two studies examining environmental predictors of heavy drinking by college students. Prevention Science, 4 (2).99108 .

[2] G. Muhammad, S. K. M. M. Rahman, A. Alelaiwi, and A. Alamri, "Smart health solution integrating IoT and cloud: A case study of voice pathology monitoring,' IEEE Commun. Mag., vol. 55, no. 1, pp. 69 73, Jan. 2017

[3] R. Kumar; M. PallikondaRajasekaran, An IoT based patient monitoring system using raspberry $\mathrm{Pi}, 2016$ International Conference on Computing Technologies and Intelligent Data Engineering (ICCTIDE'16)

[4] Jayeeta Saha1, Arnab Kumar $\mathrm{Saha}^{2}$, Aiswarya Chatterjee $^{3}$, Suyash Agrawal ${ }^{2}$, Ankita Saha ${ }^{4}$, AvirupKar ${ }^{2}$ ,HimadriNath Saha ${ }^{1,}$ IOT Based Combined Remote Health Monitoring, Home Automation and Alarm System, ${ }^{1}$ Engineering \& Industrial Services, Tata Consultancy Services, Kolkata, India ${ }^{2}$ Electrical \& Electronics Engineering, Institute of Engineering \& Management, Kolkata, India ${ }^{3}$ Computer Science \& Engineering, University of Engineering \& Management, Kolkata, India ${ }^{4}$ Electronics \&Communication Engineering, Institute of Engineering \& Management, Kolkata, India

[5] Freddy Jimenez, Romina Torres; Building an IoT aware healthcare monitoring system, 2015 34th International Conference of the Chilean Computer Science Society (SCCC)

[6] Boyi $\mathrm{Xu}, \mathrm{Li} \mathrm{Da} \mathrm{Xu}$, HongmingCai, Cheng Xie, Jingyuan $\mathrm{Hu}$ and Fenglin Bu, Ubiquitous Data Accessing Method in IoT- Based Information System for Emergency Medical Services, IEEE Transactions on Industrial informatics, 2014, Volume:10 , Issue: 2,pp 1578 - 1586.

[7] Nahla F. Omran Faculty of Science - South Valley University Qena, Egyptnahlaafathy@yahoo.com A Survey of Internet of Things Technologies and Projects for Healthcare services International Conference on Innovative Trends in Computer Engineering (ITCE 2018), Aswan University, Egypt. 
[8] D.MOHANAPRIYA "IOT Based Automation of Electricity Consumption in Smart homes" was presented on IEEE - International Conference on Systems Computation Automation and Networking March 2019

[9] P.Mathivanan(2019) "Home Automation Using Smart Mirror" in International Conference on Systems Computation Automation and Networking March 2019(ICSCAN) 10.1109/ICSCAN.2019.8878799.

[10] P.MATHIVANAN, "Remote Patient Healthcare System using IoT", in International Conference on Recent Innovations in Arts, Science and Technology, ICRIAST2018, at Lord Venkateshwaraa Engineering College, Kancheepuram, 19th March 2018.

[11] Y.YIN,Y. ZENG, X. CHEN, ANDY. FAN, “The Internet Of Things In Healthcare: An Overview," J. Ind. Inf. Integr., VOL. 1, PP. 313, MAR. 2016.

[12] Linda Bolier and Wilhelmus Johannes Maria Josephus Cuijpers. 2000. Effectieveverslavingspreventie op school, in het gezinen in de wijk (Effective Drug Prevention at School, in the Family and in the Community).GGZ Nederland.

[13] M. ALHUSSEIN, G. MUHAMMAD, M. S. HOSSAIN, AND S. U. AMIN, Cognitive Iot-Cloud Integration For Smart Healthcare: Case Study For Epileptic Seizure Detection And Monitoring, Mobile Netw. Appl., Vol. 23, No. 6, Pp. 16241635, DEC. 2018.

[14] Samir Patel, et al. Mobilizing your medications: an automated medication reminderapplication for mobile phones and hypertension medication adherence in a highrisk urbanpopulation J Diabetes SciTechnol, 7 (3)(2013), pp. 630-639CrossRefView Record in Scopus Google Scholar 